\section{An Xp11.23 deletion containing PORCN may also cause angioma serpiginosum, a cosmetic skin disease associated with extreme skewing of $\mathrm{X}$-inactivation}

European Journal of Human Genetics (2008) 16, 1027-1028; doi:10.1038/ejhg.2008.87; published online 14 May 2008

In the May 2007 issue of European Journal of Human Genetics, a three-generation family with an X-linked dominant form of a rare skin condition called angioma serpiginosum (OMIM no. 300652) was described. ${ }^{1}$ The presence of very mild nail dystrophy, with affection of no more than 1-4 nails per patient, and concomitant nonsymptomatic oesophageal papillomatosis, led to the suggestion that angioma serpiginosum might be allelic to focal dermal hypoplasia (FDH). ${ }^{1}$ The affected females' only complaint was cosmetic due to the emergence of vascular streaks along Blaschko's lines. The rash progressed from childhood to adulthood. Growth was normal, and no bodily asymmetry was present. None of the individuals had hand, eye, skeletal or other malformations commonly found in FDH patients.

The genetic cause of FDH, also called Goltz-Gorlin syndrome, was recently published. ${ }^{2,3}$ Deletions or mutations affecting PORCN, a regulator of Wnt signaling, was found in both sporadic and rare familial cases. Now, we have found that all affected females in the abovementioned Norwegian family also had a deletion containing the $P O R C N$ gene. This deletion was $112 \mathrm{~kb}$ (from 48198 to $48310 \mathrm{~kb}$ from Xpter) and removed PORCN and four other genes, i.e., just $25 \mathrm{~kb}$ smaller than a deletion previously found in FDH patients (Supplementary Figure 1). ${ }^{2}$

We suspect that it is not the minor difference in deletion size but different efficacy of protective X-inactivation that causes the phenotypic difference. In both angioma serpiginosum females and in FDH females with deletions, the X-inactivation pattern was extremely skewed. ${ }^{1-3}$ All these deletions contained at least four genes in addition to $P O R C N$. In contrast, only one of the patients with a mutation in the PORCN gene was extremely skewed. ${ }^{3}$ This variability of disease expression may depend on the timing and extent of counter-selection against cells randomly inactivating the normal X-chromosome during embryogenesis. If a deletion is inherited, the extra deleted genes (ie SLC38A5, FTSJ1, EBP, OATL1, and more variably the centromeric RBM3, WDR13 and the telomeric SSX genes) could make such counter-selection even more efficient. In a few tissues, e.g. striated epithelia (skin, oesophagus), this cell fitness-based X-selection may be less efficient, allowing escape of a few mutated cell lines. The lack of Wnt expression from these epithelial streaks may be the cause of gradual connective tissue changes with angioid malformations in the underlying mesodermal tissue. Unlike the situation in microdeletion patients, embryonic cells lacking only PORCN may not be counter-selected as efficiently. This could result in malformations due to defective Wntdependent morphogenesis later in development. Alternatively, most of the PORCN mutation-only patients may be somatic mosaics because the mutations are post-zygotic, and it is the mosaicism that makes embryonic survival possible. Evidence for such mosaicism has already been found. ${ }^{2,3}$

There are no good explanations for why the FDH-family with a $137 \mathrm{~kb}$ microdeletion ${ }^{2}$ and the angioma serpiginosum family with a $112 \mathrm{~kb}$ microdeletion affecting the same five genes except RBM3 have such a difference in phenotypic severity (Supplementary Figure 1). Patient GG1 from the FDH family had pronounced skin lesions and nail dysplasia, and in addition unilateral breast hypoplasia. ${ }^{2}$ In the angioma serpiginosum family, the skin texture was normal, and no breast hypoplasia or other signs of asymmetry have been seen. Possibly, modifying genes affecting the timing of X-inactivation during embryogenesis may have caused this difference.

\section{Gunnar Houge ${ }^{*, 1}$, Frank Oeffner ${ }^{2}$ and Karl-Heinz Grzeschik ${ }^{2}$ \\ ${ }^{1}$ Center for Medical Genetics and Molecular Medicine, Haukeland University Hospital, Bergen, Norway; \\ ${ }^{2}$ Department of Human Genetics, University of Marburg, Bahnhofstr. 7, Marburg, Germany}

${ }^{*}$ Correspondence: $\operatorname{Dr} G$ Houge, Centre for Medical Genetics and Molecular Medicine, Haukeland University Hospital, Bergen N-5021, Norway.

Tel: + 47 55975444; Fax: + 47 55975479; E-mail: gunnar.houge@helse-bergen.no 


\section{References}

1 Blinkenberg EO, Brendehaug A, Sandvik AK, Vatne O, Hennekam RC, Houge G: Angioma serpiginosum with oesophageal papillomatosis is an X-linked dominant condition that maps to Xp11.3-Xq12. Eur J Hum Genet 2007; 15: 543-547.
2 Grzeschik KH, Bornholdt D, Oeffner F et al: Deficiency of PORCN a regulator of Wnt signaling, is associated with focal dermal hypoplasia. Nat Genet 2007; 39: 833-835.

3 Wang X, Reid Sutton V, Omar Peraza-Llanes J et al: Mutations in Xlinked PORCN, a putative regulator of Wnt signaling, cause focal dermal hypoplasia. Nat Genet 2007; 39: 836-838.

Supplementary Information accompanies the paper on European Journal of Human Genetics website (http://www.nature.com/ejhg) 